\title{
O Filósofo natural num manual de Alquimia
}

\section{Química e Alquimia}

Referindo o Programa da Terceira Parte da Filosofia Natural, a Ciência Chymica, a ciência que "ensina a separar as differentes substâncias que entram na Composição de hum Corpo; a examinar cada huma das suas partes; a indagar as propriedades e analogias dellas; a comparallas e combinallas com outras substancias; e a produzir por mixturas differentemente combinadas novos Compostos", os Estatutos da Reforma Pombalina da Universidade de Coimbra, em 1772, não foram minimamente complacentes para com os alquimistas. Neles, o Reformador fez questão de deixar bem claro que "antes de entrar nas Lições desta Sciencia, dará o Lente hum Resumo abbreviado da Historia della: mostrando a origem que teve; os progressos que fez; as revoluções; os sucessos; a decadência; e o descrédito em que esteve pelos mysterios escuros dos Alchymistas, e pelas pertensões frívolas da Pedra Filosofal, e outros segredos, cuja invenção se propunham homens de maior temeridade que prudência". ${ }^{1}$

Na sua decisão firme de restauração do ensino da ciência química nos moldes das novas práticas e teorias que no resto da Europa ela conhecera "nos últimos tempos", o apelo a um corte radical com os alquimistas fazia tábua rasa do facto de serem alquimistas declarados os grandes praticantes e renovadores desta ciência nas décadas anteriores que mais haviam marcado a sua renovação, incluindo, como principais fautores, Paracelso, Van Helmont, Becher, Stahl e o próprio Newton. No contexto

\footnotetext{
* Dept. de Química, Universidade de Coimbra 3004-535 COIMBRA
}

da Revolução Cientifica Moderna, a ciência química conheceu os seus novos rumos no quadro da iatroquímica (a química ao serviço da medicina) e da química do Jardin du Roi dos séculos XVI-XVII, uma e outra totalmente informadas por uma filosofia alquimista.

Apodando de "mysterios escuros" e "pertensões frívolas da Pedra Filosofal" as práticas dos alquimistas com um apelo à sua total rejeição, o Reformador ignorava, inclusive, quanto o perfil do Filósofo Natural que os seus Estatutos traçavam podia ser decalcado de muitos textos alquímicos que então circulavam com grande aceitação pela Europa. Fazendo-o, o Reformador assumia, todavia, uma atitude que também se tornara corrente, ao tempo, na Europa, que relegaria para a escuridão quantos ousassem devotar-se às práticas químicas com intenções alquimistas. Uma atitude que atravessou todo o século XIX e grande parte do século XX e que se encontra ainda hoje a ser reabilitada.

Hoje, é cada vez maior o número de historiadores da química empenhados em repensar o papel das tentativas-eerros da alquimia no desenvolvimento da química como ciência. Recentemente, a propósito da International Conference on the History of Alchemy and Chymistry realizada de 19 a 22 de Julho de 2006, em Filadélfia (USA) na Chemical Heritage Foundation, o New York Times, na sua página de rosto e na sua secção "Science Times", pôs em relevo esse empenho. ${ }^{2}$ Sem negar que muitos daqueles que nos diferentes séculos se devotaram à Alquimia foram verdadeiros charlatães que deixaram pelas ruas do total descrédito a arte e a literatura a que deixaram ligados seus nomes, impõe-se creditar a muitas das práticas alquímicas e a muitos dos seus mais apaixonados praticantes muito do progresso científico verificado no domínio do conhecimento químico, sobretudo nos séculos XVII e XVIII, a ponto do grande historiador da Química J. R. Partington se referir muitas vezes à química como "alquimia racionalizada". ${ }^{3-4}$

Apraz-nos aqui, neste contexto, realçar o perfil do Filósofo Natural traçado pelo Médico Português Anselmo Caetano Munhós de Avreu, no seu tratado Ennoea ${ }^{5}$, escrito em 1730 e publicado em 1732 (Parte I) e 1733 (Parte II), todo ele um longo Diálogo entre Enodato (o próprio autor) e Enódio (um seu discípulo ávido das doutrinas e práticas da alquimia), num todo de mais de 300 páginas, acrescidas de 176 páginas do chamado Prólogo Galeato e mais de 70 páginas de Dedicatória, todas elas, umas e outras, centradas no mesmo assunto.

Sem entrar em pormenorizadas considerações sobre a obra e o autor do tratado em questão, diremos apenas que Anselmo Caetano Munhós de Abreu Gusmão e Castelo Branco era Doutor pela Universidade de Coimbra, familiar do Santo Ofício, Médico do Excelentíssimo Senhor Duque de Aveiro e natural da antiquíssima Vila de Soure. Bibliograficamente, para além da Ennoea, escreveu também um tratado com o título Systema Medico Galeno-Chymico, outro com o título Polymathia Medica Hermético-Galenica e ainda um outro intitulado Vieira Abbrviado. ${ }^{6-7}$

Estamos em crer que caso tivesse conhecido e considerado devidamente o perfil do Filósofo Natural traçado por Anselmo Caetano na referenciada Ennoea, apresentado como exigência natural para a prática frutuosa da Chymica e o descobrimento da Chrysopeia, pois se os homens tanto suão e trabalham para viver e terem com que vivão, em 
nenhuma Arte devem trabalhar e suar mais do que no estudo da Chymica, e no descobrimento da Chrysopeia ${ }^{8}$, talvez o Reformador da Universidade de Coimbra tivesse encontrado nele a introdução bastante para a definição do objectivo da Faculdade de Filosofia Natural criada pelos Estatutos e se tivesse dispensado da injusta referência ao descrédito que à química teria advindo dos "mysterios escuros dos Alchymistas e das pertensões frívolas da Pedra Filosofal".

\section{O sonho de Enodato}

É no Diálogo II do seu tratado Ennoea que Anselmo Caetano Munhós de Avreu refere explicitamente e com toda a clareza o perfil do "consumado Filósofo" que há-de ser o apanágio supremo do verdadeiro Adepto, na procura e preparação da Pedra Filosofal. Ele "há-de ser homem de claro entendimento, profundo juízo, subtil discurso, grande compreensão e bom engenho"; e, sobretudo, "consumado na Filosofia", "perito na língua latina, inteligente da Mathematica, versado na lição dos livros Chymicos, para que o estudo aperfeiçoe o entendimento, e o entendimento illustrado alcance grandes segredos com a subtileza do juízo, e os reduza a pratica com o bom engenho". Para tanto, "além de todas estas qualidades há de ter industria, constância, riqueza, prudência, sossego, paciência e segredo". 9

É porém, na descrição do seu sonho alquímico que apresenta no Diálogo III que esse perfil é melhor explanado e realçado. ${ }^{10}$

Depois da conversa de longas e longas horas que Enodato tivera com Enódio, aduzidas todas as razões e todos os factos em favor da existência da Pedra Filosofal, e, a seu ver, rebatidos todos os argumentos de que se servem os nãoherméticos para a negarem, sentindo que já mais nada tinha para declarar sobre o assunto, Enodato entrega a Enódio um papel em que escrevera na manhã do dia anterior um sonho que tivera. Era como que um teste passado ao discípulo para fazer a avaliação do quanto ele havia compreendido de toda a conversa que com ele havia tido: se fosse capaz de o interpretar, dever-se-ia sentir consolado; se o não entendesse, não se deveria sentir surpreendido porque se tratava de facto, de um sonho misterioso, mas não se "deveria aplicar então ao estudo da Chymica porque não tiraria dele qualquer fruto". ${ }^{11}$

Depois de ter ponderado todos os enigmas com que os Adeptos explicaram a Ars Magna, Enodato adormeceu e sonhou que estava embarcado num navio que fustigado por violenta e furiosa tormenta se desfez, tendo ele sido arrojado, abraçado a uma tábua, para uma praia deserta a que se seguiam, terra adentro, uns dilatados e desconhecidos campos, totalmente desérticos e despovoados, sem quaisquer culturas, nem estradas, nem veredas. O deserto, a aridez, a sensação de nada saber, eis os primeiros sentimentos de quem se propõe encetar a dura caminhada que o leve à prática da Ars Magna do verdadeiro praticante da alquimia, num requisito de virtude, fé e trabalho paciente. "Ora, lege, relege, labora et invenies".

Em pleno deserto, Enodato viu-se mergulhado num mundo de miragens. Era como se estivesse na cidade de Morgana, essa cidade do Reino de Nápoles, onde, "no meio dos vapores do ar, aparecem com tão admirável como repentina architectura, Castellos e Palácios com arcos magníficos e colunas equidistantes, e estas em tão grande numero, (...), mais de dez mil, todas belíssimas, com proporção e cor admirável, e pouco a pouco desvanecendo os primeiros objectos, succedem, como em differentes scenas e aparências, bosques ameníssimos, ciprestes e arvores mayores em fileiras, e campos abertos, cheyos de homens, e gados de muitas castas". 12

Mercê da sobreposição de diferentes camadas de ar com diferente grau de rarefacção e, consequentemente, diferente índice de refracção, os raios luminosos provenientes de um mesmo ponto de qualquer objecto dão origem a uma distribuição de pontos-imagem numa longa linha vertical. Formam-se assim uma infinidade de imagens virtuais de um mesmo objecto. Nas costas do estreito de Messina, as condições atmosféricas são propícias à ocorrência deste fenómeno. Homero na Odisseia, Virgílio na Eneida, Ovídio nas Metamorfoses e Dante na Divina Comédia o haviam constatado. Hoje a Física explica-o com naturalidade com as suas explicações dos fenómenos ópticos, como explica a infinidade de imagens virtuais de um objecto posto entre dois espelhos para- lelos. Mas antes de se ter encontrado esta explicação, outras foram as explicações. Num mundo de duendes e fadas, ele tornou-se um fenómeno lendário. Por ali andara a Fada Morgana, essa figura lendária dos celtas, irmã do rei Artur que com ele casou e de quem teve filhos, e que o protegeu quando caiu morto. Ligada pois ao grande arauto da busca do Santo Graal. Não surpreende por isso, que o fenómeno fosse particularmente objecto de especulações para os Adeptos da Alquimia, tido como um fenómeno de luz e sombra da Arte Magna.

O padre Atanásio Kircher a quem Anselmo Munhós de Abreu tem sempre presente ao longo de toda a Ennoea, pois é seu objectivo refutar todos os argumentos por ele aduzidos contra a existência do "grande mysterio da Arte Magna", servindo-se deles para provar a mesma, designa o fenómeno em causa de "maravilhoso apparato". E no seu propósito de impugnar os mistérios da Arte Magna, com toda a clareza afirma que ele se explica por "razões naturaes, fundadas na Catóptrica, pela proporcionada mistura de luzes e sombras, formando-se no meyo dos vapores mais crassos, oppostos ao monte, huma opacidade, com vários ângulos de incidência e reflexão, da qual resulta um perfeito espelho polyedro, que de um só objecto, v. g. de huma so columna, que acaso estará na praya, se reflecte huma prodigiosa multidão de columnas". Assim, "de huma árvore se faz um bosque, de hum homem se faz um exército". ${ }^{13}$ Falando do seu sonho, Enodato sabe desta explicação, mas sente-se melhor com o maravilhoso. A noção de espelho presente na explicação avançada por Kircher poder-Ihe-ia ter servido para referir a simetria entre o mundo que habitamos e o mundo donde a alma se eleva, na axiomática do grande princípio da Tábua de Esmeralda de que o que está em cima é como o que está em baixo, o microcosmos, a imagem múltipla da reflexão do macrocosmo.

Como está no deserto, Enodato sente-se bem com uma explosão de energia que caracteriza este primeiro estado da sua caminhada rumo ao reino onde mora o grande Artífice da Arte Magna. Situado ainda do lado de cá do espelho, sente-se confortado com a multiplicação maravilhosa de si mesmo num vislumbre 
que Ihe dá a força necessária para caminhar no meio de tanta aridez.

O deserto onde as coisas são miragem de luz e sombra é o lugar próprio para o Adepto iniciar a sua iniciação. No princípio, no seu gérmen, a Obra é nigro; é na confusão primordial dos elementos, na corrupção da semente, no húmido e cálido útero materno, que o Adepto deve iniciar a sua obra de síntese. É no deserto, no Caos tenebroso tornado miragem e abismo, que a dissolução das matérias seminais da Obra se dá para que se torne possível a resolução dos elementos em Mãe-Água.

Mas, iniciada a caminhada, rapidamente começa a fazer-se luz, com o sol a raiar à sua frente. Da miragem rapidamente se passa para um mundo onde as coisas são reais, palpáveis e sedutoras; às trevas segue-se o belo do colorido, onde se realça o verde da esperança que dá alento ao caminhar do viandante.

Rapidamente, Enodato se encontra num vale que ficava entre dois montes muito altos, cheio de plantas pequenas de muitas e diversas cores e figuras, porque não só eram verdes, mas brancas, amarelas, azuis, pardas e negras. Todas elas muito viçosas, embora ali não houvesse água, nem ninguém que as regasse ou cultivasse. No termo do vale, umas serras muito altas, cobertas com um admirável e delicioso bosque em que as árvores tinham troncos, ramos e folhas cobertos de cinzas e frutos. E no fim das serras, num outeiro mais baixo, uma árvore singular, a árvore do conhecimento que os textos sagrados colocam no centro do Paraíso, essa àrvore de cujo fruto Adão comeu infringindo a ordem do seu criador. Junto dela, um venerável Ancião que Ihe iria servir de guia no resto da caminhada. ${ }^{14}$

É aqui, em pleno bosque, que começa a iniciação do Adepto no seu encontro com o Ancião, em estrita consonância com aquilo que Enodato já antes afirmara a Enódio, repetindo o que S. Bernardo escrevera a um amigo: mais se aprende nos bosques do que nos livros, porque nos bosques acha-se Deus que é a verdadeira fonte da sabedoria, e nos livros acha-se muita ignorância dos homens. ${ }^{15}$

O venerável Ancião era um velho na idade, mas um renovado Mancebo na plenitude das suas faculdades físicas, cheio de força e saúde e com as mais perfeitas cores, e, sobretudo, na plenitude das suas faculdades mentais. Era um Filósofo e como tal passa a ser designado por Enodato no resto da narração do seu sonho. Um Filósofo que servia como primeiro-Ministro da poderosíssima Imperatriz que reinava naquela terra em que se encontrava e servia de guia a todos os peregrinos que a essa terra chegassem.

Sabendo que os Monarcas do mundo inteiro são vassalos e feudatários dessa toda poderosa Imperatriz a quem o Ancião servia como primeiro-ministro, logo Enodato pensou tratar-se da Santíssima Trindade porque só "Deus Trino e Uno he verdadeiro Rey dos Reys e Senhor dos que dominam o Mundo". Mas estava enganado no seu pensamento. Embora Soberana Senhora, a Imperatriz não é Deus, mas criatura sua, com mais de natural que de divina. ${ }^{16} \mathrm{O}$ Ancião logo ali the atalhou esse seu engano: a Imperatriz a quem servia como primeiro-Ministro era a Natureza. Ele era seu guia no caminho que o conduziria a seu trono porque é a Filosofia que leva ao verdadeiro conhecimento da Natureza e permite explicar os mistérios da prodigiosa quinta que é seu reino.

Este encontro onírico com o Ancião e nesta primeira revelação que ele Ihe fez sobre quem era e sobre quem era a Imperatriz a quem servia como primeiro-ministro, Enodato via consagradas aquelas qualidades do verdadeiro Adepto que referira já a seu discípulo Enódio quando Ihe dissera: "há-de ser homem de claro entendimento, profundo juízo, subtil discurso, grande compreensão e bom engenho"; e, sobretudo, "consumado na Filosofia". Porque "consumado na Filosofia", o verdadeiro Adepto deveria ser também "perito na língua latina, inteligente da Mathematica, versado na lição dos livros Chymicos, para que o estudo aperfeiçoe o entendimento, e o entendimento illustrado alcance grandes segredos com a subtileza do juízo, e os reduza a pratica com o bom engenho". Para tanto, "além de todas estas qualidades há de ter industria, constância, riqueza, prudência, socego, paciência e segredo". ${ }^{17}$

Nele temos o retrato quase perfeito do verdadeiro estudioso da Natureza, o fi- lósofo natural, na certeza de que a Filosofia é a alma de todos os conhecimentos humanos; sem ela não será possível conhecer-se devidamente a Natureza. E sem a conhecer não é possível fazer como ela faz. Ela é a ciência da Razão e a contemplação da Natureza. Não se pode pois ter acesso à soberana Imperatriz que domina sobre todas as coisas se não se for verdadeiro filósofo: um iniciado na Filosofia Racional que dirige as operações do entendimento e prepara os primeiros princípios de todas as ciências; e um iniciado na filosofia natural que transpondo as duas grandes portas do conhecimento da Natureza, a observação e a experiência, leve ao conhecimento dos Princípios que a regem e das Leis em que é possível traduzi-los.

Para bem operar, o Adepto tem de se mover continuamente nos meandros da Nova Ciência, essa Ciência que N. Tartaglia, em 1537, na sua figuração do encontro das disciplinas matemáticas com a Filosofia apresenta a ocupar a parte mais interior e altaneira duma fortaleza, onde, na entrada imediata, a entrada interior, Aristóteles e Platão recebem o estudante que a ela se dirige; e no exterior, dirigindo-se ao seu encontro, o estudante se encontra com Euclides que o entrega às disciplinas matemáticas (a Aritmética, a Geometria, a Astronomia, a Astrologia), na presença do próprio Tartaglia, dirigindo-se, então, todos juntos para o local da Filosofia. ${ }^{18}$ Ela é a Razão que uns anos antes, em 1532, o nosso João de Barros, na sua Ropicapneuma, a Mercadoria Espiritual do Tempo, do Entendimento e da Vontade, localizava na "melhor e mais forte torre do castelo em que habita", re-afirmando a doutrina de Platão, reforçada, nesses anos por Erasmo no seu Enchiridion: a Razão tem sede e assento na parte mais alta de todo o corpo, o cérebro, a mais próxima do céu, a torre mais alta da cidade humana, onde lhe é devida homenagem como a rei que a tudo preside e medeia; a sua excelência advém-Ihe duma lei eterna que Deus nela imprimiu, mercê da qual sempre se inclina para o bem, resistindo tenazmente a todas as seduções. ${ }^{19-20}$

Consumado na Filosofia, o Adepto não pode ser nunca um divorciado da ciência natural por mais que venha a concluir, num discurso de verdadeiro 
misticismo, que a "verdadeira Pedra Filosofal he a graça de Deos que communica à alma a virtude de purificar os Metaes dos cinco sentidos, e converter em Prata e Ouro para a coroa da gloria as nossas obras" onde "o húmido supérfluo que os Chymicos devem tirar he o luxo; o sulphureo ardor he o fogo da luxúria; a negridão corrompente he a mácula do pecado; as fezes terrestres que estorvão os progressos da obra, são o amor aos bens da terra que contamina a pureza do espírito". É que de facto, "nesta obra concorrem também as operações Chymicas, a saber, Sublimação, quando se levanta a alma ao conhecimento do Altíssimo; Precipitação, quando conhece a sua baixeza; Calcinação, com o pensamento nas cinzas da morte; Solução, liquação e distilação, nas lágrimas da penitência; Coagulação e Fixação, na constância da Fé e firmeza no amor de Deos". ${ }^{2}$ E só o bom cientista conhece bem todas estas operações e está preparado para as realizar com a perfeição desejada.

A verdadeira Pedra Filosofal está escondida no seio da Natureza. É lá que o Adepto a pode encontrar; e só o conseguirá conhecendo profundamente essa mesma Natureza, nos seus mais recônditos meandros, e sabendo manipular todas as artes e técnicas que o possam levar até ao seu âmago. Ser um bom cientista é pois, requisito necessário para vir a ser um bom Adepto. Aquele que não for um verdadeiro sábio, não espere encontrar-se nunca com a Pedra Filosofal porque não é possível explicar os segredos da Natureza a quem não tiver percebido os mistérios da Filosofia.

No pressuposto de que para se ser um verdadeiro Adepto é necessário ser um "consumado Filósofo", Enodato, nas suas conversas com Enódio, salientou, em particular a necessidade de ser "perito na língua latina, inteligente da Mathematica, e versado na lição dos livros Chymicos". O latim era ao tempo de Anselmo Caetano de Munhós, a matriz linguística da cultura científica. O verdadeiro filósofo, no seu estudo da Natureza não pode deixar de estar em diálogo contínuo com todos aqueles que por esse mundo fora, estão empenhados na mesma tarefa; com eles deve trocar os seus conhecimentos e deles deve saber receber os conhecimentos de que eles são senhores. Esse diálogo torna-se difícil e pouco eficaz fora da necessária matriz linguística. Hoje, Anselmo Caetano diria, possivelmente, aos seus discípulos que para se ser um bom cientista é preciso ser perito na língua inglesa! O inglês ou uma outra qualquer língua que sirva adequadamente de matriz à fácil comunicação científica é cada vez mais um imperativo para se ser um bom cultor de qualquer ciência.

E não surpreende a referência específica à necessidade que o Filósofo da Natureza tem de ser "inteligente da Mathemática e versado na lição dos livros Chymicos". Focando a necessidade da matemática, ele poder-se-ia ter reportado a Galileu que na questão 6 do seu tratado O Ensaiador, escrito em 1623, afirmara com toda a convicção: "a fiIosofia do Universo esse grandíssimo livro que continuamente está aberto em frente de nossos olhos, não se pode entender sem primeiro se conhecer a linguagem e os caracteres em que está escrita. A sua linguagem é uma linguagem matemática em que os caracteres são os triângulos, os círculos e demais figuras geométricas, sem o conhecimento dos quais é impossível entender uma só das suas palavras". ${ }^{22} \mathrm{E}$ sobre a necessidade de ser versado nos livros químicos bastará referir que é pela química que a Natureza é dissecada, num processo de análise e síntese, para bem se compreender a sua composição e os mecanismos de sua acção.

A "industria (como diligência de acção intelectual), constância, riqueza, prudência, sossego, paciência e segredo" são qualidades universalmente reconhecidas e se espera sejam apanágio de toda a actividade científica, sem as quais ela rapidamente degenera e se torna fogo fátuo.

\section{Notas}

1 Estatutos Pombalinos da Universidade de Coimbra, 1772, Liv.III, Pt.III, Tit.III,Cp.IV, n.2

2 J. N. Wilford, Transforming the Alchemists in New York Times, August 1, 2006

3 J.R.Partington, A History of Chemistry, vol.I (MacMillan \&Co Ltd.Londres 1970) pp.XI-XVIII.
4 A.M.Amorim da Costa, Alquimia, um Discurso Religioso, Lisboa, Pub.Vega,1999, pp.18-23.

5 Anselmo Caetano Munho's de Abreu Gusmão e Castelo Branco, Ennaea [sic], ou applicação do entendimento sobre a Pedra philosophal provada, e defendida com os mesmos argumentos com que os Reverendíssimos Padres Athanasio Kircher no seu Mundo Subterraneo, e Fr. Bento Hieronymo Feyjoo no seu Theatro Crítico, concedendo a possibilidade, negão, e impugnão a existencia deste raro e grande mysterio da Arte Magna, - (Parte I: Lisboa Occidental, Officina de Maurício Vicente de Almeida, 1732; Parte II: Lisboa Occidental, Nova Officina de Maurício Vicente de Almeida, 1733). Edições facsimiladas: (a) - Y.Centeno, Fundação Calouste Gulbenkian, Lisboa, 1987; (b) - MM, Mafra, 1987.

6 M. J. Gandra in Nota Preambular à Edição fac-similada de Ennoea ou Aplicação do Entendimento sobre a Pedra Filosofal (Mafra, Rolo \& Filhos, 1987), pp.28-29.

7 A.M. Amorim da Costa, Alquimia, um Discurso Religioso, Lisboa, Pub .Vega, 1999, pp.121-132; Idem, O Sonho Alquímico de Enodato e o Perfil do Filósofo Natural in VI Encontro Internacional "Discursos e Práticas Alquímicas, Guimarães, 22-24 de Junho de 2006. http://triplov.com /coloquio_06/ amorim da costa

8 Anselmo Caetano Munho's de Abreu Gusmão e Castelo Branco, o. Cit., Prologo Galeato, p.161.

9 Idem, Dialogo II, cp.unico, §2, pp.9-10.

10 Idem, Dialogo III, cp.unico, §8, p.67-80.

11 Idem, Dialogo III, cp.unico, §8, p.67.

12 Idem, Dialogo III, cp.unico, §8, p.67.

13 Idem, p.68-69..

14 Idem, pp.69-70.

15 Idem, Dialogo II, cp.unico, §3, p.29.

16 Idem, Dialogo III, cp.unico, §8, p.72.

17 Idem, Dialogo II, cp.unico, §2, p.9-10.

18 N. Tartaglia, Nova Scientia. Veneza, 1537, vol.1, p.2).

19 João de Barros, Ropica Pnefma, Lisboa, Lisboa Galharde, 1532.

20 A.M.Amorim da Costa, O Mundo Epistemológico de Ropicapnefma (1532) de João de Barros in História da Ciência: o Mapa do conhecimento, Edusp, S.Paulo, 1995, vol.2, pp-217-235.

21 Anselmo Caetano Munho's de Abreu Gusmão e Castelo Branco, o. Cit, Dialogo III, cp. unico, §10, p.94.

22 Galileo-Galilei, II Saggiatore, Roma, 1623, in Opere XVIII, p.293. 

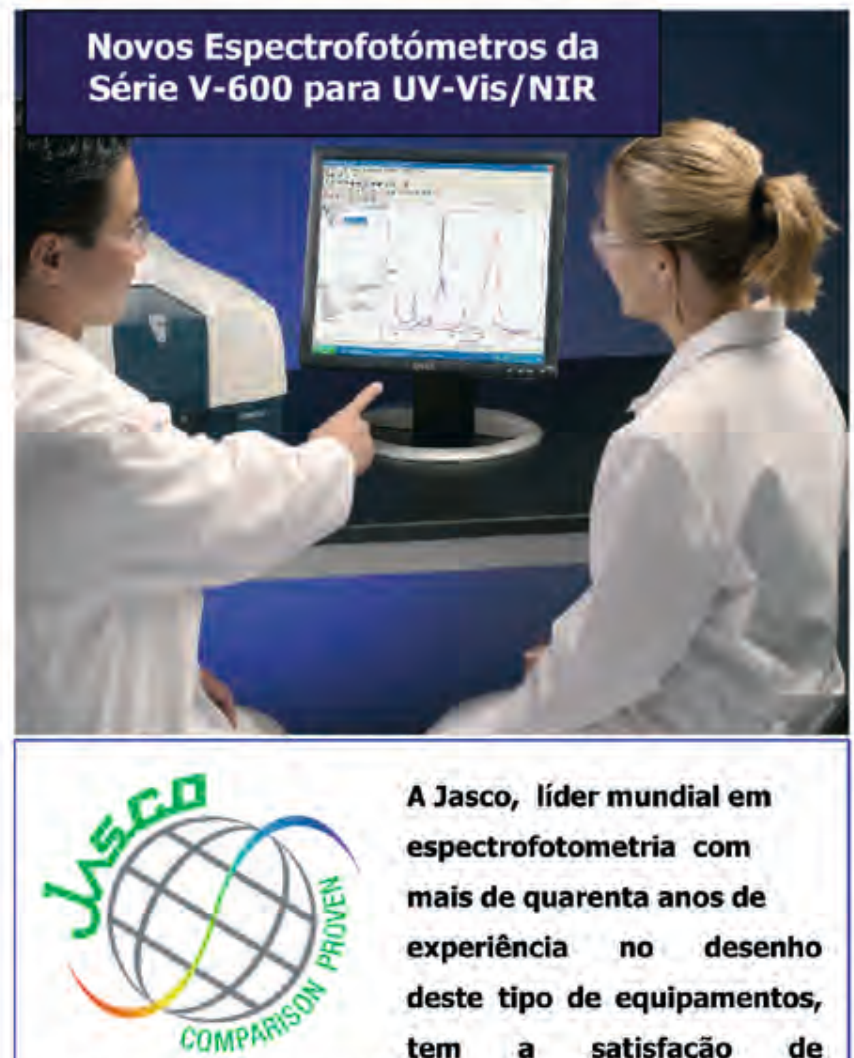

A Jasco, líder mundial em espectrofotometria com mais de quarenta anos de experiência no desenho deste tipo de equipamentos, tem a satisfação de introduzir no mercado uma nova linha de espectrofotómetros para UV-Vis/NIR. A série V-600 consiste de cinco modelos distintos desenhados para ir de encontro às necessidades de milhares de clientes em todo o mundo. Uma disposição óptica inovadora e um software de controle e análise de dados de fácil utilização garantem a exactidão, o desempenho e a fiabilidade requeridas para este tipo de aparelhos. A JASCO orgulha-se do desenvolvimento com sucesso de equipamentos analíticos rompendo com tradições estabelecidas e tem fundadas esperanças no sucesso desta poderosa linha de produtos. A JASCO juntamente com a Elnor, garantem inteiramente a fiabilidade e o desempenho destes equipamentos, fornecendo adicionalmente uma gama completa de serviços de apoio ao cliente.

Para mais Informações:

Rua D. Frei Jerónimo de Brito e Melo, no 8354465 - 642 Leça do Balio Telefone: 229050400

Fax: 229050499 e-mail: info@elnor.com Web: www.elnor.pt

\section{Desenho compacto}

$O$ desenho óptico compacto da série V600 reduz exigências de espaço no laboratório moderno.

\section{Excelente desempenho óptico}

A luz difusa reduzida permite medidas altamente precisas sobre uma escala fotométrica larga.

\section{Varrimento a alta velocidade}

A elevada saída do sistema óptico e detectores rápidos permitem varrimentos a alta velocidade sem erros ao longo do comprimento de onda seleccionado.

\section{Correcção de fundo}

A redução da luz difusa permite medidas de elevada exactidäo em amostras de absorvância elevada.

\section{Varrimento passo a passo do} monocromador

A funçăo da varrimento passo a passo permite a atribuição fiável do pico de absorçăo em amostras com os picos afiados ou estreitos.

\section{Interfaces Gráficas de fácil acesso}

Novo módulo iRM remoto inteligente

Software Manager ${ }^{\mathrm{rM}}$ II e Spectra

Manager CFR

\section{Acessório de IQ}

Acessório de automático

reconhecimento de acessórios.

\section{Arranque de IQ}

Para arranque automático de qualquer programa registado por pressão simples da tecla "Arranque".

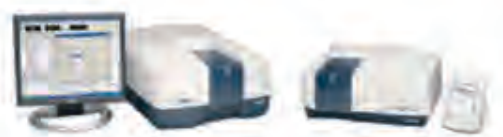

Gama completa de acessórios

Mais de cinquenta suportes diferentes para análise de amostras gasosas. liquidas e sólidas com caracteristicas especificas.

\section{Exactidão e fiabilidade}

O equipamento é fornecido em conformidade com as normas USP, EP e JP. Como opção pode ser fornecido com rotinas de $I Q / O Q$.

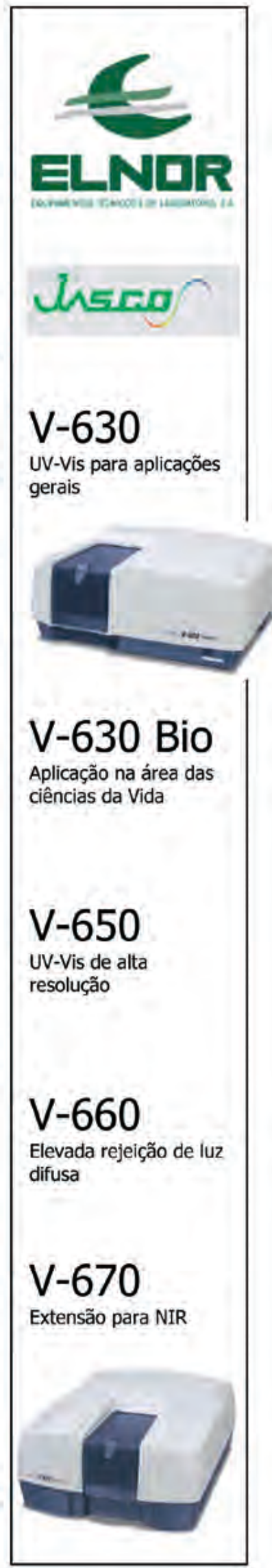

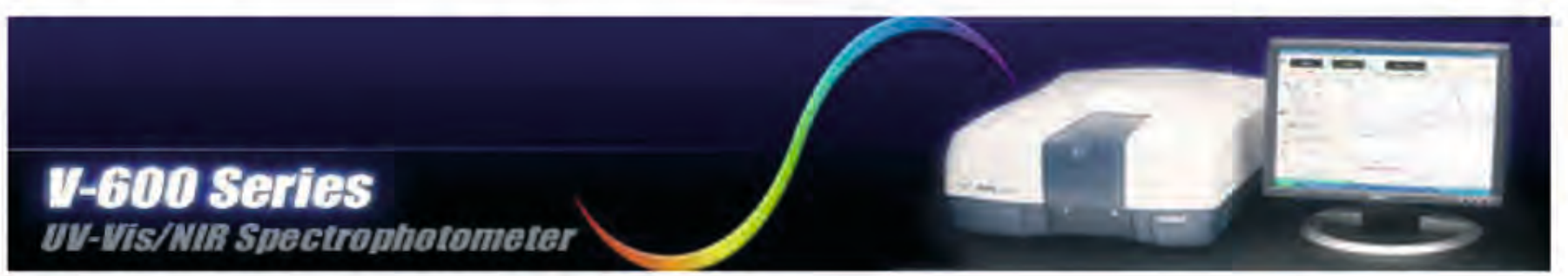

